\title{
Present and future multiterminal HVDC systems: current status and forthcoming developments
}

\author{
G. Buigues, V. Valverde, A. Etxegarai, P. Eguía, E. Torres \\ Department of Electrical Engineering, Faculty of Engineering of Bilbao, UPV/EHU \\ Alameda de Urquijo s/n, 48013 Bilbao (Spain) \\ e-mail: garikoitz.buigues@ehu.eus
}

\begin{abstract}
Considering the importance that HVDC systems are expected to have in the future of power networks, this paper aims to provide a wide overview of the worldwide existing technologies and installations in the field of MTDC-HVDC systems. In particular, it analyses and describes both classic LCC-MTDC systems and present/future VSC-MTDC systems, the latter being based on multi-level converter technology. This way, it is expected that this paper will draw the attention of those researchers looking for a starting point, from where to be able to develop new analysis and developments that increase the applicability of future HVDC systems.
\end{abstract}

\section{Key words}

LCC-HVDC, VSC-HVDC, MTDC, multi-level converter, DC grids.

\section{Introduction}

During the last decades, the way in which the different energy sources are integrated into the power system has undergone significant changes, mainly because of the extensive development of new renewable generation technologies: photovoltaics, on- and off-shore wind, etc. Nowadays, due to the commitment from the European Union to reduce $80 \%$ in Greenhouse Gas emissions by 2050, significant quantities of renewable energies are increasingly being added to the generation mix. Since most of the renewable resources are located in remote locations, where AC power systems are weak or nonexistent, the concept of a European High-Voltage Direct Current (HVDC) "Supergrid" has emerged as an interesting possibility for the future.

Although HVDC is a well-proven technology, the feasibility of the HVDC solution is of special importance in offshore wind farms. Most of offshore wind farms that have been built to date are relatively close to shore, but the large offshore transmission distances envisaged, along with the need for extra requirements (multidirectional power flow, enhanced control, etc.), limit the choice of the transmission technology to be considered. Besides, even well-known conventional DC systems (Line Commutated
Converter, LCC) are unlikely to be able to meet the requirements of future networks.

In this context, the less mature Voltage Source Converter (VSC) technology and VSC-HVDC based multiterminal DC grids (MTDC), along with modular multi-level converters (MMC), are set to become the core of future HVDC meshed networks.

This way, this paper is intended to provide a wide overview of the existing and projected HVDC-MTDC real installations, from the MTDC systems based on the classic LCC-HVDC technology, to the deployment of the most recent VSC-HVDC systems and the use of MMC technology in their MTDC installations.

\section{Present and future multiterminal HVDC systems}

The successful application of two terminal DC links around the world suggested that greater economic and technical advantages might be realized by a MTDC system, where three or more DC converters are interconnected by a DC transmission network [1]. Its architecture is more complex as compared to the one of a point-to-point system. This way, these systems can be classified in three main groups [2]:

- Radial MTDC systems, where each converter station is connected to a single DC line.

- Meshed or Ring MTDC system, where each converter station is connected to more than one DC line.

- Series-connected MTDC system, where all the converter stations are connected in series.

Implementation of future meshed HVDC grids is solely feasible with voltage source converters (VSC) that are subdivided in two-, three- und multi-level converters (either using modular multilevel converters MMC or Alternate Arm Converters AAC). Since multi-level converters have many advantages over the other 
technologies, it can be seen that future HVDC grids are going to be based on this technology [3].

\section{LCC-MTDC systems}

\section{A. LCC-Technology}

Conventional thyristor-based HVDC systems (LCCHVDC) are based on a well-proven technology that offers a high power transmission capacity, but with limited reactive power control. Furthermore, the increased complexity of the master control, the need for fast communications links and the inability to change the direction of the current may have constituted the reasons why MTDC HVDC networks using LCC-HVDC technology decrease its development or even stopped being developed [4].

\section{B. Hydro-Québec-New-England}

The Hydro-Québec-New England (Canada) multiterminal HVDC system project was developed in two different phases (Fig. 1) [4]:

- Phase I, finished in October 1986, in which only two terminals were commissioned connecting Des Cantons station (near Sheerbrooke, Québec) to Comerford station (near Monroe, New Hampshire). This line was $172 \mathrm{~km}$ long, operated at a bipolar direct voltage of \pm $450 \mathrm{kV}$ and carried $690 \mathrm{MW}$ (rated power of each station).

- Phase II, in which three more converter stations were installed. The Radission converter station (2250 MW), in Québec, and the Sandy Pond converter station (2000 MW), in Boston, were finally commissioned in 1990. Finally, in 1992, Nicolet converter station (2138 MW), near Montreal, was commissioned.

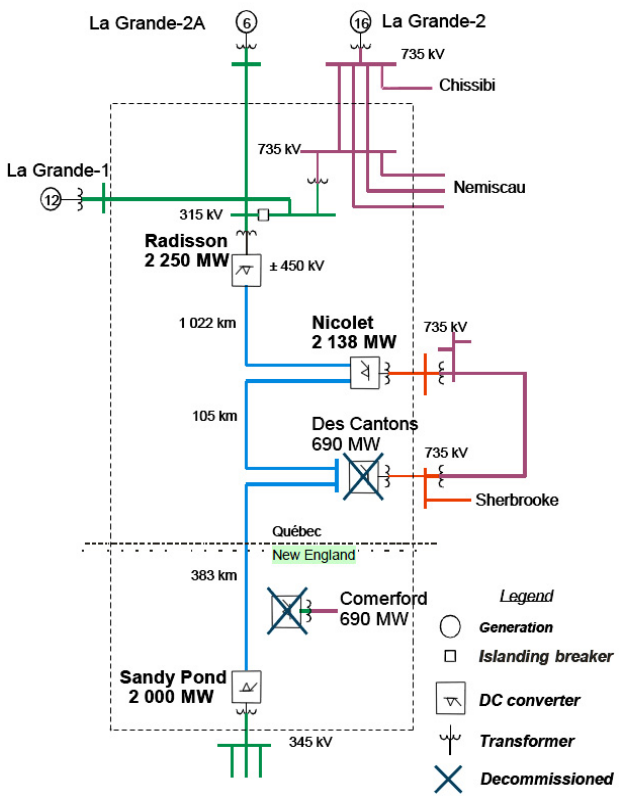

Fig. 1. Hydro-Québec - New-England scheme [5]

Although Comerford and Des Cantons converter stations were supposed to be integrated into the multi-terminal scheme, the owners finally decided to suspend the commercial integration of these two stations, mainly due to performance issues [6].

\section{SACOI interconnection}

The first phase of the SACOI (Sardinia-Corsica-Italy) interconnection was commissioned in 1967 as a point-topoint 200MW $200 \mathrm{kV}$ monopole interconnection between San Dalmazio (mainland Italy) and Codrongianos (Sardinia). This link of monopolar type operated at a voltage $\pm 200 \mathrm{kV}$ d.c. and included two $200 \mathrm{MW}$ converter stations, equipped with mercury arc valves, connected through two conductor lines, sized for a total power capacity of $300 \mathrm{MW}$, partly in submarine cables and partly in overhead lines, with sea return. A third converter station of 50MWcapacity was commissioned in 1988, making it an MTDC station. This station was equipped with air cooled thyristor valves $[7,8]$.

In 1992, the stations at Dalmazio and Codrongianos were decommissioned and replaced by other stations (located in Codrongianos in Sardinia and Suvereto in Tuscany), rated to $300 \mathrm{MW}$ and equipped with air cooled thyristor valves (Fig. 2). This new link was called SACOI 2 [7, 8].

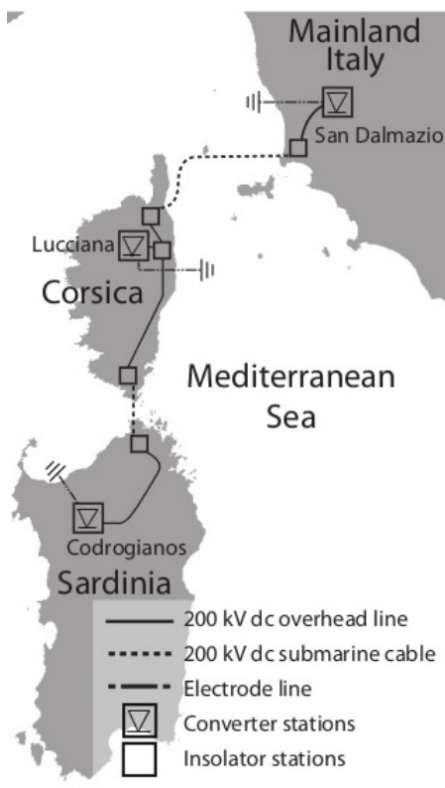

Fig. 2. SACOI interconnection [9]

\section{North-East Agra}

After more than 20 years, the first multiterminal UHVDC system called North-East Agra (NEA, $\pm 800 \mathrm{kV}, 6000$ MW, $1728 \mathrm{~km}$ ) is under construction in India [2]. This project will initially have three converter stations, at Biswanath Chariali, Alipurduar and Agra, and will be configured as two bipoles paralleled onto a single HVDC line (Fig. 3). In Phase 1 of the project, there will be one bipole terminal at each of Biswanath Chariali and Alipurduar, each rated at $3000 \mathrm{MW}$. Later, in a Phase 2 upgrade of the project, a second bipole will be built at each of Biswanath Chariali and Alipurduar, bringing their installed capacity to $6000 \mathrm{MW}$ each. The first of Biswanath Chariali or Alipurduar to be uprated will 
remain connected to Agra, while the other will be separated from the Phase 1 system and form an independent $6000 \mathrm{MW}$ transmission on a new DC line to a new inverter station, yet to be defined [10].

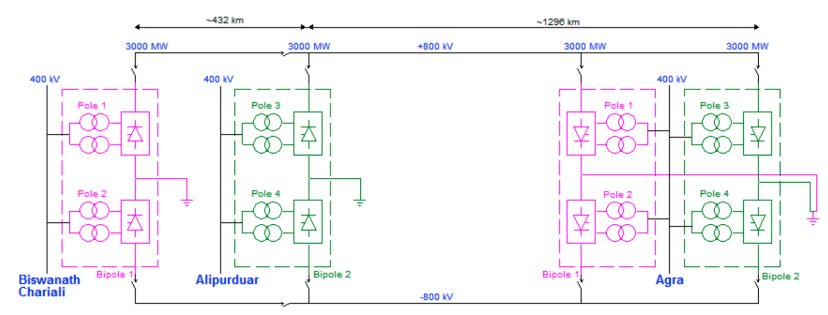

Fig. 3. North-East Agra system [11]

\section{VSC-MTDC systems}

\section{A. VSC-MTDC technology}

The VSC technology has been used for point-to-point HVDC transmission since the late nineties. This is still a developing technology unlike the LCC, which is mature and well-proven. The VSCs typically use IGBTs with antiparallel diodes. Due to the late development and relatively low available capacity, the deployment of VSC technology has been limited to only a small fraction of the overall HVDC installed capacity worldwide. However, there is enormous potential for VSC-HVDC, especially for offshore applications. Similar to the conventional AC networks, the power reversal in a particular VSC HVDC link within an MTDC grid is achieved simply by reversing the current through that link while maintaining the voltage polarity at both ends. Thus, the VSC technology is the obvious and arguably the only choice for meshed DC grids [8].

VSC-HVDC schemes are commonly referred to with their brand names [12]: HVDC Light (ABB), HVDC Plus (Siemens), or HVDC MaxSine (Alstom Grid/GE). There are also some Chinese manufacturers. Currently, they are based on multi-level converter technology.

\section{E. Nan'ao island}

Nan'ao island is in the southern part of the Guangdong province, China. The key objectives of the project were to incorporate the existing and future wind power generated on Nanao island into the regional power grid, both to safeguard future energy supply and to support the transition from coal towards renewable sources. This project implied the world's first multi-terminal VSCMTDC system, which was successfully commissioned on December $25^{\text {th }}, 2013$ [13].

The project includes two stages (Fig. 4). During stage I, three terminals in the system are connected. They are the Jinniu (JN) station (100 MVA, Nan'ao Island), Qing'ao (QA) station (50 MVA, Nan'ao Island) and Sucheng (SC) station (200 MVA, Mainland, China). In stage II, the offshore wind farm Tayu will be connected to the system as the fourth terminal. The conductors between stations are made up of a mixture of overhead lines and cables [14].

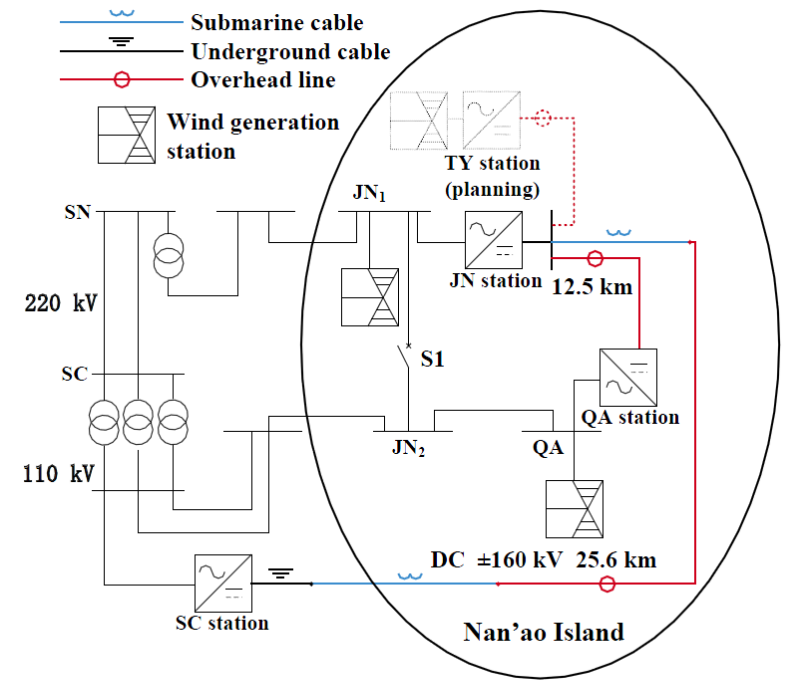

Fig. 4. Nan'ao project configuration [14]

The Nan'ao VSC-MTDC system is an AC/DC parallel power transmission system, and each converter station is connected to the $110 \mathrm{kV}$ AC system. The DC voltage of the entire project is $160 \mathrm{kV}$ and the $\mathrm{DC}$ side of the converter employs the symmetric monopole configuration [14]. Each converter station consists of AC circuit breaker, converter transformer $(110 / 166 \mathrm{kV})$, precharge resistor (to limit the current for converter charging), bypass switch, modular multilevel converter (MMC) and disconnectors at the DC side [15]. DC breaker technology is not mature and economical at present, so it was not used in this project [14].

\section{F. Zhoushan islands}

The Zhoushan archipelago is located in China's eastern coastal region, consisting of more than 1390 islands. Among the islands of the Zhoushan archipelago, the larger and more power-consuming islands include the main island of Zhoushan, followed by the islands of Daishan, Qushan, Yangshan and Sijiao. To meet the increasing demands of the construction of new areas and development of different islands, the power load capacity will need to increase constantly [16].

Considering the status of Zhoushan's existing power grid and the future demand for electrical load, the construction of the Zhoushan DC grid system will be divided into three stages (Fig. 5): The first stage is to build the five-terminal DC transmission system (commissioned and put into service on June $27^{\text {th }}, 2014$ ), in order to improve the reliability of power supply for these islands and the ability to accept wind power. The second stage is to build the five-terminal DC transmission system with DC breakers (successfully installed on December $29^{\text {th }}, 2016$ ), so as to improve the fault clearance and recovery abilities as well as system availability, and conduct engineering inspections of the DC breakers under development. The third stage is to construct the five-terminal DC grid system [16]. 


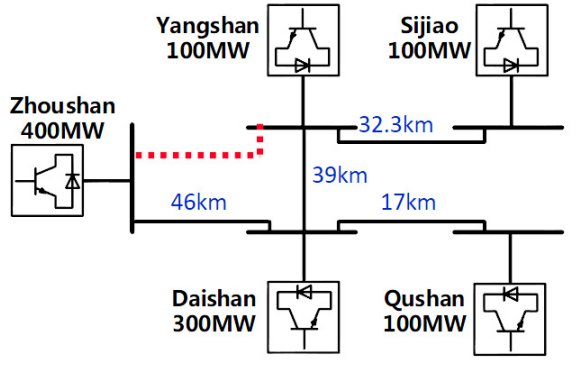

Fig. 5. Zhoushan DC system configuration [17]

The five converters rated at $\pm 200 \mathrm{kV}$ in the Zhoushan DC grid are connected via modular multi-level voltage source converter (MMC-VSC) HVDC links to form a 5-terminal DC grid. The converter stations used in this system incorporate symmetric monopole main wiring mode and the cables connect the converters with a total length of 140 $\mathrm{km}[16,18]$.

A full-bridge cascaded new-type topology of the hybrid circuit breaker was designed for this project, which comprises three parallel branches including the main branch, transfer branch, and energy-consuming branch [16]. These HVDC circuit breakers have rated voltage $200 \mathrm{kV}$, rated current $2 \mathrm{kA}$, short-circuit current breaking capacity $15 \mathrm{kA}$, breaking time of $3 \mathrm{~ms}$ and transient voltage $300 \mathrm{kV}$ [19].

\section{G. Atlantic Wind Connection}

The Atlantic Wind Connection (AWC) Project is the first offshore backbone electrical transmission system proposed in the United States. The AWC Project would enable up to 7000 megawatts (MW) of offshore wind turbine capacity to be integrated into the regional high-voltage grid in the heavily congested corridor between Virginia and the metropolitan New Jersey/New York City area. This HVDC subsea backbone transmission system would be constructed off the coasts of New York, New Jersey, Delaware, Maryland, and Virginia [20].

The AWC project is being developed in phases in order to meet the needs of the transmission grid and offshore wind development (Fig. 6). The initial development of the project is anticipated to be the New Jersey Energy Link (NJEL), which will consist of 3 converter stations, 3 converter platforms, and associated HVDC cables to facilitate transmission of up to $3000 \mathrm{MW}$ of offshore wind power (estimated completion date 2020/2021). Subsequent phases of the project will consist of the Delmarva Energy Link (DEL), which will connect wind development off the coasts of Delaware, Maryland, and Virginia into the PJM system, and the Bay Link, which will ultimately connect NJEL to DEL to form an HVDC grid consisting of 12 converter stations and converter platforms [21].

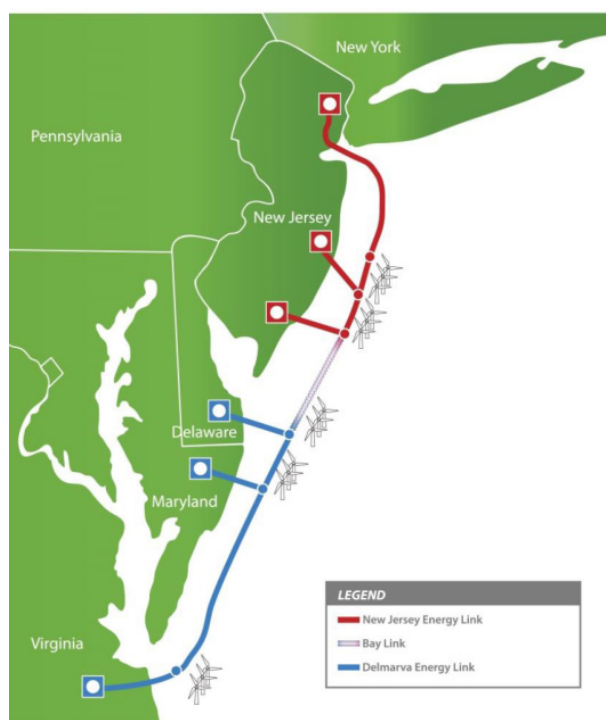

Fig. 6. Atlantic Wind Connection project [21]

The converters in the AWC system will be rated $1000 \mathrm{MW}$ at $\pm 320 \mathrm{kV}$ and will be configured as a symmetrical monopole.

\section{H. DC grid project in Zhangbei}

Zhang-Bei is designed as a DC grid project to secure power supply to Beijing from a variety of clean sources, including wind, solar and hydro power. Four converter stations will be built for phase I, including 3 sending terminals $(1500 \mathrm{MW} / \pm 500 \mathrm{kV}$ each $)$ and one receiving terminal $(3000 \mathrm{MW} / \pm 500 \mathrm{kV})$. When completed in 2018 , it will become the first and largest DC grid project in the world. Another two terminals have also been planned for phase II (Fig. 7), with commissioning expected in 2021 [22].

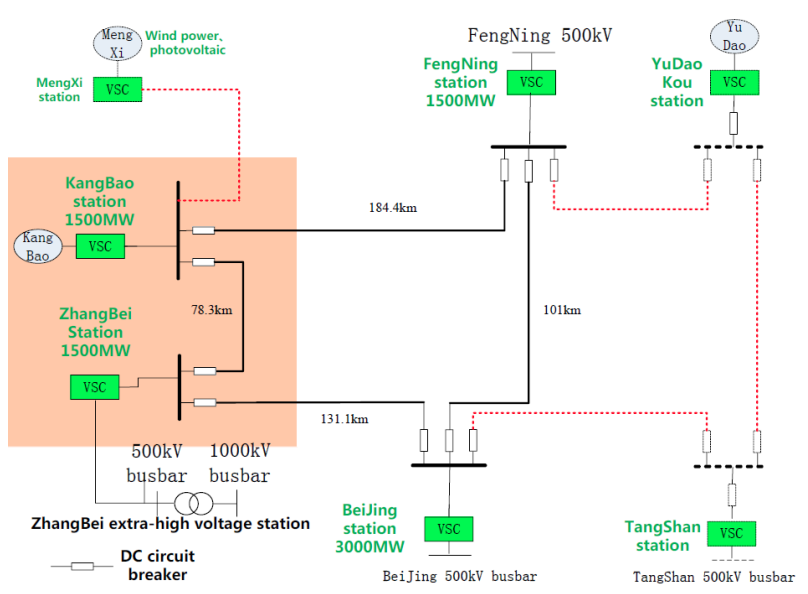

Fig. 7. HVDC grid topology in Zhangbei [23]

The project adopts "Half Bridge MMC + DC Breaker" scheme [23]. In fact, the DC breaker developed in the Zhoushan project will also serve as a pilot project for the DC breaker to be developed in the Zhangbei DC grid [24].

\section{Other related installations and projects}

Apart from the previous ones, which are clearly MTDC systems, there are other projects and installations that, at 
some point of their development, were considered or may be used as multiterminal systems.

The Tres Amigas Supestation project is intended to provide $5000 \mathrm{MW}$ of power transmission at the confluence of three asynchronous grid systems in the south-west U.S.A. (WECC, SPP and ERCOT) [25]. Although the initial project called for the development of a threeterminal HVDC Bus with the potential use of High Temperature Superconductor Cable (HTSC) and HVDC Power Circuit Breakers (HVDC-PCB) systems, in 2010 the concept was revised and current plans call for a more or less traditional power transmission node. This way, the final project comprises $3 \times 750 \mathrm{MW}$ VSC and $3 \times 920 \mathrm{MW}$ LCC converters. Each of the converters will be configured in a new concept call "folded Back to Back" in order that the HVDC bus $(\sim 300 \mathrm{kVdc})$ is exposed to allow the future possibility of HVDC-PCB switching and the utilization of future HTSC cables to extend the TASS system to further extend the node concept. This project was to begin its construction in 2013 but it was not until November 2015 that the first phase was started $[26,27]$.

The South-West Link is a combined alternating current (AC) and voltage source converter HVDC-VSC transmission line totalling $427 \mathrm{~km}$ in length, which reinforces the transmission grid between mid- and southern Sweden. The northern part of the link is a $176 \mathrm{~km}$ $400 \mathrm{kV}$ AC overhead line (OHL) between the substations Hallsberg and Barkeryd. The southern part is a $251 \mathrm{~km}$ direct current (DC) transmission line between the substations Barkeryd and Hurva, which is divided into two parts: $61 \mathrm{~km}$ OHL and $190 \mathrm{~km}$ underground cable [28]. Phase 2 of the project was intended to extend the HVDC scheme to Tveiten (near Oslo) in Norway, converting the project to a multi-terminal interconnection between Sweden and Norway, which explains the name of the project, The South West Link (SydVästlänken) [29]. However, in 2013, the project for a western branch between Barkeryd and Oslo area was cancelled on Norwegian initiative [30].

The initial project for the Moray Firth was to support the inclusion of an offshore HVDC hub in the route of a subsea HVDC link from Shetland already in planning and that would run close to the sites of future offshore windfarms in the Moray Firth, northeast Scotland. However, in 2012, there was insufficient justification for inclusion of the hub in the HVDC link as part of to the Caithness reinforcement solution, so the project was terminated [31]. Instead, an $320 \mathrm{kVdc}$ HVDC link will be created between Caithness and Moray, including two landbased converter stations, one rated at 1,200 MW at Blackhillock in Moray and another rated at $800 \mathrm{MW}$ situated at Spittal in Caithness. The link is scheduled to become operational in 2018. Furthermore, considering the expected future link to Shetland from Caithness, the equipment delivered under this contract will have the capability to handle such a multi-terminal set up [32].

The COBRA CABLE project consists of the installation of a sub-sea HVDC $320 \mathrm{kVdc}$ cable connecting the Dutch and Danish electricity markets, integrating wind energy into the supply systems in both countries and investigating the technical, economic and regulatory aspects of connecting offshore wind farms to the cable. It will use VSC-HVDC converters, have a capacity of 700 MW, will be around 325 kilometres long, and will run from Eemshaven (the Netherlands) to Endrup (Denmark) via the German sector of the North Sea [33]. Given the funding received by the European Energy Programme for Recovery (EEPR), this project must consider the (future) possibility to connect offshore wind farms to COBRA cable, as a first step towards a meshed North Sea offshore grid, so the VSC technology was chosen [34]. It is expected to begin its construction during 2016 and to be commissioned by 2019 .

\section{Conclusion}

This paper is intended to provide a wide overview of the existing technologies and installations in the field of MTDC-HVDC systems, including those based on classic LCC technology, but with a special attention to the most recent and innovative VSC-MTDC systems that use multi-level converter technology.

\section{Acknowledgement}

The authors thank the support from the Spanish Ministry of Economy, Industry and Competitiveness (project ENE2016-79145-R AEI/FEDER, UE), the Basque Government (projects ELKARTEK 2016 KK$2016 / 00038$ and research group funding IT1083-16), as well as from the University of the Basque Country UPV/EHU (project EHUA15/25).

\section{References}

[1] C.-K. Kim, V. K. Sood, G.-S. Jang, S.-J. Lim, and S.-J. Lee, HVDC Transmission: Power Conversion Applications in Power Systems, 2009.

[2] M. Eremia, C.-C. Liu, and A.-A. Edris, Advanced Solutions in Power Systems. HVDC, FACTS, and Artificial Intelligence, 2016.

[3] A. K. Marten, C. Troitzsch, and D. Westermann, "Non-telecommunication based DC line fault detection methodology for meshed HVDC grids", in AC and DC Power Transmission, 11th IET International Conference on, 2015, pp. 1-8.

[4] R. Teixeira, "Multi-Terminal DC Networks System Integration, Dynamics and Control", Thesis submitted in fulfilment of the requirements for the degree of Doctor of Philosophy, Delft University of Technology, 2014.

[5] D. McNabb, "Feedback on the Québec - New England Multiterminal HVDC Line: 20 years of Operation", in Cigreé B4 Open Session, Paris (France), 2010.

[6] Québec - New England. The first large scale multiterminal HVDC transmission in the world to be upgraded. Available: 
http://new.abb.com/systems/hvdc/references/queb ec-new-england

A. Ardito, L. Camilli, C. D. Mario, A. Giorgi, G. Pazienza, C. Pincella, M. Rebolini, R. Rendina, G. Simioli, G. P. Stigliano, and D. Tagliatesta, "Feasibility of a new long distance submarine HVDC link between Sardinia and the Italian mainland", in CIGRÉ General Session, Paris (France), 2004.

[8] N. Chaudhuri, B. Chaudhuri, R. Majumder, and A. Yazdani, Multi-terminal Direct-Current Grids: Modeling, Analysis, and Control: Wiley-IEEE Press, 2014.

[9] R. Teixeira, P. Bauer, and J. Enslin, "Challenges on the road to future High-Voltage Multi-terminal DC Networks", in 16th Conference on Power Electronics and Applications (EPE'14-ECCE Europe), Lappeenranta (Finland), 2014.

[10] N. L. Shore, A. Gangadharan, A. Kumar, and A.K. Skytt, "DC Harmonic Filter Design and Mitigation of Induced Fundamental Frequency Currents for the NEA $800 \mathrm{kV}$ HVDC Multiterminal Project", in CIGRE SC B4 Meeting and International Tutorials \& Colloquium on HVDC and Power Electronics, Agra (India), 2015.

[11] N. Kumar, R. Kumar, M. S. Rao, M. M. Goswami, B. B. Mukherjee, and O. Chandy, "Commissioning Experience and Challenges of World's First $800 \mathrm{kV}, 6000 \mathrm{MW}$ NER - Agra Multi terminal HVDC System", in CIGRÉ Session, Paris (France), 2016.

[12] D. Van Hertem, O. Gomis-Bellmunt, and J. Liang, HVDC Grids. For Offshore and Supergrid of the Future: Wiley, 2016.

[13] G. Bathurst and P. Bordignan, "Delivery of the Nan'ao multi-terminal VSC-HVDC system", in 11th IET International Conference on $A C$ and DC Power Transmission, 2015, pp. 1-6.

[14] H. Rao, "Architecture of Nan'ao multi-terminal VSC-HVDC system and its multi-functional control", CSEE Journal of Power and Energy Systems, vol. 1, pp. 9-18, 2015.

[15] X. Li, Z. Yuan, J. Fu, Y. Wang, T. Liu, and Z. Zhu, "Nanao multi-terminal VSC-HVDC project for integrating large-scale wind generation", in 2014 IEEE PES General Meeting | Conference \& Exposition, 2014, pp. 1-5.

[16] G. Tang, Z. He, H. Pang, X. Huang, and X. p. Zhang, "Basic topology and key devices of the five-terminal DC grid", CSEE Journal of Power and Energy Systems, vol. 1, pp. 22-35, 2015.

[17] T. An, "Fault Clearance for Zhoushan HVDC System", in 2014 China International Conference on Electricity Distribution (CICED), Shenzhen (China), 2014.

[18] Y. Pipelzadeh, B. Chaudhuri, T. C. Green, Y. Wu, H. Pang, and J. Cao, "Modelling and Dynamic Operation of the Zhoushan DC Grid: World's First Five-Terminal VSC-HVDC Project", in International High Voltage Direct Current Conference, Seoul (Korea), 2015.

[19] J. Zhou, H. Li, R. Xie, L. Liu, W. Nie, K. Song, F. Huo, and D. Liang, "Research of DC circuit breaker applied on Zhoushan multi-terminal VSC-HVDC project", in 2016 IEEE PES AsiaPacific Power and Energy Engineering Conference (APPEEC), 2016, pp. 1636-1640.

[20] "Unsolicited Right-of-Way Grant Application for the Atlantic Wind Connection Project", Ecology and Environment, Inc., 2011.

[21] P. V. I. Taiarol, G. A. MacPhail, V. S. Pathirana, and B. Mampaey, "The Atlantic Wind Connection - Building the Foundation for Offshore Wind Energy", in CIGRÉ Belgium Conference, Brussels (Belgium), 2014.

[22] SGRI Participates in Construction of Zhang-Bei DC Grid Pilot Project. Available: http://www.cepri.com.cn/release/details_66 745 .html

[23] T. Guangfu, "High Power Conversion Technology for High Voltage DC Transmission Application", in The Energy Conversion Congress and Exposition (ECCE), Milwaukee (United States of America), 2016.

[24] C-EPRI Participates in the World's First DC Circuit Breaker Project. Available: http://www.cepri.com.cn/release/details_66 759 . $\mathrm{html}$

[25] N. M. Macleod, N. M. Kirby, D. Stidham, and M. Reynolds, "Tres Amigas : an innovative HVDC link between three asynchronous AC networks", in Cigre B4 Colloquium, Melbourne (Australia), 2011

[26] J. Kumagai, "The U.S. may finally get a unified power grid", IEEE Spectrum, vol. 53, pp. 35-36, 2016.

[27] N. M. Kirby, N. M. Macleod, D. Stidham, and M. Reynolds, "Tres Amigas : A flexible gateway for renewable energy exchange between the three asynchronous AC networks in the USA", in Cigré Session, Paris (France), 2012.

[28] U. Moberg, "Spotlight on Smart and Strong Power T\&D Infrastructure Ver2.0 (Sweden)", International Smart Grid Action Network (ISGAN)2016.

[29] D. Ingemansson, J. D. Wheeler, N. M. MacLeod, F. Gallon, and O. Ruiton, "The South-West scheme: A new HVAC and HVDC transmission system in Sweden", in 10th IET International Conference on $A C$ and DC Power Transmission (ACDC 2012), 2012, pp. 1-5.

[30] Changes in conditions. Available: http://www.svk.se/en/grid-

development/network-development-

plan/changes-since-last-plan/

[31] "Offshore HVDC Hub Project", Scottish and Southern Energy2015.

[32] (2015, Creating Scotland's Caithness Moray subsea HVDC power link. Available: http://www.abb.com/cawp/seitp202/3f413ceb17 7da589c1257e11004f3605.aspx

[33] "COBRAcable. From concept to connection", Tennet, Energinet.dk.

[34] "COBRACable. Business Case Description", TenneT2013. 